\title{
COMITÊ DE ÉTICA EM PESQUISA COM SERES HUMANOS DA UFSM: UM ESTUDO SOBRE AS PRINCIPAIS PENDÊNCIAS NA APROVAÇÃO DE PROJETOS
}

http://dx.doi.org/10.5902/2318133867392

\author{
Gabriela Heinz ${ }^{1}$ \\ Luis Carlos Zucatto²
}

\begin{abstract}
Resumo
Inicialmente motivada pelas descobertas das atrocidades ocorridas em experimentos no período da $2^{\text {a }}$ Guerra Mundial, a ética em pesquisa tornou-se tema recorrente no meio científico. Ela visa a orientar os pesquisadores na condução de suas atividades, a fim de resguardar os participantes da pesquisa contra eventuais riscos e danos e também assegurar a potencialização dos benefícios, com retorno social. Nesse sentido, o Conselho Nacional de Saúde instituiu, em 1996, a Comissão Nacional de Ética em Pesquisa para gerenciar os comitês de ética em pesquisa, os quais avaliam projetos de pesquisas que envolvam seres humanos. Com base nesse contexto, definiu-se como objetivo deste estudo identificar as pendências mais recorrentes nos pareceres emitidos pelo Comitê de Ética em Pesquisa com Seres Humanos da Universidade Federal de Santa Maria. Os dados foram coletados na Plataforma Brasil, atendo-se aos pareceres emitidos pelo CEP/UFSM no período de 2016 a 2019, os quais totalizaram 1.128. A amostra, com parâmetros de intervalo de confiança de $95 \%$ e margem de erro de $5 \%$ resultou em 376 pareceres a serem analisados. Na análise dos dados se observou a orientação de Bardin (2011), com categorias de análise definidas à posteriori. As pendências encontradas nos pareceres dizem respeito a aspectos do termo de consentimento livre e esclarecido, metodologia, formalidades necessárias nos demais documentos obrigatórios e informações discordantes fornecidas no projeto, Plataforma Brasil e documentos anexados. Conclui-se que seus usuários carecem de atividades de capacitação sobre a elaboração de documentos e legislação.

Palavras-Chave: comitê de ética em pesquisa; Plataforma Brasil; ética em pesquisa.
\end{abstract}

\section{ETHICAL COMMITTEE ON HUMAN RESEARCH AT THE UFSM: A STUDY ON THE MAIN PENDINGISSUES IN THE APPROVAL OF PROJECTS}

\begin{abstract}
Initially motivated by the discoveries of the atrocities that occurred in experiments during World War II, research ethics became a recurrent theme in the scientific environment. It aims to guide researchers in the conduct of their activities, in order to protect research participants from possible risks and harms and also to ensure the potentiation of benefits, with social return. In this sense, the National Health Council established in 1996 the National Commission on Research Ethics to manage the research ethics committees, which evaluate research projects involving human beings. Based on this context, the objective of this study was to identify the most recurrent pending issues in the opinions issued by the Committee on Ethics in Research with Human Beings of the
\end{abstract}

\footnotetext{
1 Universidade Federal de Santa Maria, Brasil. E-mail: gabheinzz@gmail.com.

2 Universidade Federal de Santa Maria, Brasil. E-mail: luiszucatto@gmail.com. 
Federal University of Santa Maria. Data were collected in Platform Brazil, focusing on the opinions issued by the CEP/UFSM in the period from 2016 to 2019, which totaled 1,128. The sample, with confidence interval parameters of $95 \%$ and margin of error of $5 \%$ resulted in 376 opinions to be analyzed. In the data analysis the guidance of Bardin (2011) was observed, with categories of analysis defined after the event. The pending issues found in the opinions relate to aspects of the Informed Consent Form, methodology, formalities required in the other mandatory documents, and discordant information provided in the project, Platform Brazil and attached documents. It is concluded that its users lack training activities on the preparation of documents and legislation.

Key-words: committee for ethics in research; Platform Brazil; research ethics.

\section{Introdução}

1 ética ronda a sociedade de modo geral em múltiplas dimensões e se insere na prática profissional e na atividade científica. Nas pesquisas com seres humanos a expressão 'ética em pesquisa' ganhou força após virem à tona os experimentos realizados com prisioneiros da Segunda Guerra Mundial (Guilhem; Diniz, 2014). A partir deste fato passou-se a debater o tema e diversos documentos foram publicados a fim de regulamentar a condução de pesquisas que envolvessem seres humanos como sujeitos de pesquisa. Entre eles pode-se citar o Código de Nuremberg, Declaração Universal de Direitos Humanos, Declaração de Helsinque, Declaração Universal sobre Bioética e Direitos Humanos, entre outros (Brasil, 2012).

A ética em pesquisa tem como missão "proteger os sujeitos envolvidos, garantindo a todos que os seus interesses serão considerados acima dos interesses da ciência e ou da sociedade (especialmente de grupos sociais mais poderosos)" (Freitas; Hossne, 2002, p. 5). Basicamente visa-se a garantir a autonomia e a dignidade dos participantes, proteção contra qualquer tipo de dano que a pesquisa possa causar comprometimento com a potencialização dos benefícios advindos da atividade e a preocupação com o retorno social das pesquisas (Brasil, 2012).

No Brasil a primeira normativa a respeito do tema data de 1988, por meio de uma iniciativa do Conselho Nacional de Saúde, com a resolução n. 01/88. Anos depois, com a baixa aderência dos pesquisadores, foi criado um grupo de trabalho que daria origem ao marco da regulamentação ética em pesquisa no país: a resolução n. 196, de 10 de outubro de 1996 (Brasil, 2008). A partir de 1996, com a criação sistema CEP/Conep, as instituições que desenvolvessem atividades de pesquisa com seres humanos deveriam constituir um comitê de ética em pesquisa, que passaria a ser responsável pela avaliação dos protocolos de todas as áreas do saber. Os CEPs são colegiados independentes de caráter consultivo, deliberativo e educativo. Sua composição deve ser interdisciplinar, com representantes de diversas áreas do conhecimento e representantes externos dos usuários (Rego; Palácios, 2012).

Em 2012 houve a revogação da resolução n. 196/96 e a publicação da resolução $n$. 466/2012, que permanece como um guia aos pesquisadores sobre o comportamento ético necessário na condução das pesquisas científicas. Muito embora o documento mencione a necessidade de que todos os projetos envolvendo participantes de pesquisa passem por uma avaliação ética, muitas lacunas foram encontradas no que diz respeito às pesquisas nas Ciências Sociais e Humanas, pois o caráter da normativa prioriza aspectos da área da Saúde (Grisotti, 2015). Para suprir essas lacunas publicou-se a resolução $n$. 
510, em 7 de abril de 2016, que trata especificamente de aspectos pertinentes à ética em pesquisa nas Ciências Sociais e Humanas e busca solucionar dificuldades percebidas e atender a demanda de muitos pesquisadores, que estariam como que em um limbo normativo.

Algumas pesquisas desenvolvidas por pesquisadores brasileiros buscaram preencher as lacunas encontradas, porém, observa-se que os estudos acerca do tema ainda são incipientes e necessitam de maior aprofundamento, principalmente no que tange as dificuldades dos usuários no processo de aprovação de projetos. Neto e Franco (2019), por exemplo, buscaram verificar as publicações disponíveis na Scielo até 24 de junho de 2018 e chegou a um total de 41 . No entanto, verificou-se que a maioria das publicações era de caráter teórico com análises exploratórias sobre a função dos CEPs e pontos negativos relacionados às suas formas de atuação. Os assuntos mais abordados foram intromissão dos CEPs na metodologia dos projetos, formas de análises de pesquisas nas Ciências Sociais e Humanas, burocracia e importância da aprovação dos CEPs. Da amostra apenas dois estudos consideraram a perspectiva dos usuários em suas metodologias.

O CEP da Universidade Federal de Santa Maria atendeu cerca de 444 pesquisadores e avaliou cerca de 715 projetos/ano entre os anos de 2016 e 2019. Em 2016 , do total de avaliações realizadas, 58,14\% resultaram em aprovação, 39,32\% em pendência e 2,54\% em reprovação/arquivamento. Em 2017, 55,65\% das avaliações foram aprovadas, $38,50 \%$ ficaram pendentes e $5,85 \%$ foram reprovadas ou arquivadas. A partir do ano de 2018 ocorreu um pequeno aumento na taxa de aprovação, passando para $65,33 \%$ das avaliações, com $32,35 \%$ de pendência e 2,32\% de reprovação/arquivamento, mantendo os índices estáveis para o ano de 2019 (Plataforma Brasil, 2019). Por este motivo considera-se importante que a equipe do CEP/UFSM tenha o conhecimento das principais pendências para se buscar formas de mitigá-las.

A partir do exposto definiu-se como objetivo identificar as pendências mais recorrentes nos pareceres emitidos pelo Comitê de Ética em Pesquisa com Seres Humanos da Universidade Federal de Santa Maria, a fim de se buscar melhorias. Além do que já foi mencionado, a realização deste estudo é relevante, pois observou-se uma lacuna teórica devido ao baixo número de produções científicas destinadas a tratar do tema. Observa-se também que, apesar de ainda não existir uma lei que obrigue a tramitação de projetos por um CEP, é crescente o número de periódicos e eventos que solicitam um parecer de aprovação ética para o aceite de artigos, além disso, em muitos órgãos públicos este parecer também é requerido para a liberação de coletas de dados locais.

\section{Plataforma Brasil}

Desde 2012, com a resolução n. 466/2012, a Plataforma Brasil é o sistema único e exclusivo para a operacionalização do Sistema CEP/Conep, que permite a realização de atividades de controle e acompanhamento de protocolos (Brasil, 2012). Para Araújo e Francisco (2016) a criação da Plataforma acompanhou uma tendência nacional de estimular o controle social a partir da adoção de tecnologias que favorecem 0 compartilhamento de informações e a interlocução entre os interessados e os envolvidos. Atualmente são vinculados à Plataforma Brasil e à Conep 850 comitês de ética em

\begin{tabular}{|l|l|l|l|l|l|}
\hline Regae: Rev. Gest. Aval. Educ. & Santa Maria & v. 10 & n. 19 & e67392, p. 1-14 & 2021 \\
\hline
\end{tabular}


pesquisa de universidades e institutos de pesquisa distribuídos no país. Barbosa, Corrales e Silbermann (2014) resumem as funcionalidades da Plataforma Brasil:

Neste sistema é possível aos pesquisadores preencher os dados dos projetos, inserir toda a documentação pertinente, submeter o projeto ao CEP, acompanhar seu andamento no sistema, receber o parecer consubstanciado logo após realização da reunião, responder às pendências apontadas nos projetos, iniciar 0 processo de acompanhamento dos projetos aprovados e encaminhar relatórios. Ao CEP e á Conep cabe encaminhar os projetos aos pareceristas, revisar os projetos, redigir pareceres, inserir a pauta e a realização de reuniões, analisar as respostas das pendências, apreciar as notificações e emendas (acompanhamento dos projetos aprovados), enviar pareceres consubstanciados aos pesquisadores e analisar e emitir pareceres sobre os relatórios enviados pelo pesquisadores. Além disso, em sua página inicial, os números de projetos submetidos aos CEP e às Conep estão disponíveis para consulta pública. (p. 3)

O sistema comporta todos os elementos necessários para a operacionalização do Sistema CEP/Conep, constituindo-se também como um valioso banco de dados das pesquisas. Porém, Lopes-Júnior et al. (2016) mencionam que, apesar da agilidade que a Plataforma trouxe na avaliação ética de projetos, ela ainda não foi adaptada para atender as especificidades das áreas de Ciências Sociais e Humanas, e possui uma interface voltada para as pesquisas clínicas, configurando como um obstáculo aos pesquisadores da área. Um dos pontos enfatizados por Mello (2016) é de que a plataforma requer o preenchimento de pontos que não se aplicam a todas as pesquisas com seres humanos. Um exemplo é a obrigatoriedade de informar o número exato de participantes do estudo, e sem esta informação não é possível o trâmite prosseguir, porém, para muitos tipos de pesquisas este dado só será definido conforme a condução da coleta de dados. Para a autora o sistema é complicado na utilização, e mesmo com a leitura de manuais encontrase dificuldade, pois o site não atende a critérios básicos de usabilidade na web, definidos por uma norma ISO.

É reconhecido que a definição da Plataforma Brasil, como meio de tramitação de projetos para algum CEP, facilitou o trabalho dos pesquisadores, pois a partir do acesso à internet é possível dar andamento no processo de aprovação e monitoramento das pesquisas. Porém, a forma com que ocorreu a transição do trâmite da documentação em meio físico para meio online foi alvo de críticas, pois o seu lançamento aconteceu sem que ainda se estivesse pronto, gerando sucessivas atualizações e causando confusão e dificuldade nos seus usuários. Há manuais disponíveis na página da Plataforma Brasil, que apresentam os passos a serem cumpridos durante a sua utilização, contudo, todos os CEP têm a autonomia em exigir especificidades no preenchimento das informações e na documentação a ser anexada (Araújo; Francisco, 2016).

\section{Método do estudo}

Este estudo foi orientado pela abordagem qualitativa e visou a conhecer as principais dificuldades vivenciadas pelos usuários do CEP/UFSM no processo de submissão e aprovação de projetos de pesquisa. 
Inicialmente foi realizado o acesso na Plataforma Brasil no item 'relatórios de pareceres emitidos', a fim de mapear as pendências dos pareceres emitidos nos anos de 2016 a 2019. O período inicial foi selecionado devido à publicação da normativa mais recente vigente sobre ética em pesquisa, a resolução n. 510/2016. Para cada ano, a plataforma forneceu um arquivo executável no Software Microsoft Office Excelß com a lista em ordem decrescente e cronológica de todos os pareceres emitidos no período. Assim, foram excluídos os pareceres de emendas/notificações e os de aprovação, mantendo apenas aqueles com a situação de pendência, retirados e não aprovados. $O$ número de pareceres na situação supracitada no período, de acordo com os relatórios, foi 1.128. Desse modo foi realizado o cálculo da quantidade mínima necessária de pareceres para análise a partir da seguinte fórmula.

Figura 1 -

Cálculo do tamanho da amostra.

$$
n=\frac{Z_{\alpha / 2}^{2} \cdot \hat{p} \cdot \hat{q} \cdot N}{e^{2}(N-1)+Z_{\alpha / 2}^{2} \cdot \hat{p} \cdot \hat{q}}
$$

Fonte: Lopes (2020).

No cálculo apresentado considera-se: $\mathrm{N}=$ tamanho da população, $\mathrm{Z}=$ distribuição normal padrão (tabela), $q=$ percentual estimado da proporção, $p=1-q, e=$ erro amostral e $\alpha=$ nível de significância. Foi utilizado para $Z$ o valor tabelado de 1,96 (Dist. Normal Padrão), erro amostral de $5 \%$, nível de significância de $95 \%$ e percentual estimado de 50\% (Lopes, 2020). Com isso chegou-se ao número de, no mínimo, 288 pareceres necessários. Os pareceres selecionados para análise foram escolhidos por amostragem sistemática, com uma ordenação de intervalos iguais definidos a partir da divisão entre o total de pareceres e o número necessário (1128/288), resultando em um intervalo de 3,92. O valor obtido foi arredondado para menos, para que fosse possível alcançar o número mínimo. Assim, a cada três pareceres ordenados cronologicamente ano a ano, um foi acessado na Plataforma Brasil, lido e analisado, totalizando 376 pareceres. Além disso, destaca-se que um mesmo projeto poderia ter mais de uma pendência e elas são listadas separadamente no relatório gerado na Plataforma Brasil. Dessa forma, optou-se por analisar apenas o primeiro parecer consubstanciado pendente emitido e, no caso de um projeto aparecer repetidamente, escolheu-se desconsiderar e analisar o parecer seguinte.

As categorias de pendências foram definidas posteriormente, ao longo da análise, de acordo com as emergências do estudo e, uma vez realizada a seleção dos pareceres, procedeu-se à leitura e análise de conteúdo Bardin (2011). Ressalta-se que a análise de conteúdo qualitativa vai muito mais além da contagem de palavras e concepções, pois visa também a interpretar as relações existentes entre os termos e, assim, tirar conclusões e apontar alguns prognósticos (Rossi; Serralvo; João, 2014). A definição como 
qualitativa diz respeito à etapa inicial de leitura e interpretação de pareceres, gerando dados que podem ser quantificáveis. Durante o andamento das análises de conteúdo dos 376 pareceres, foram detectadas 925 pendências, definidas em categorias e subcategorias conforme explicitado a seguir:

a) Termo de consentimento livre e esclarecido/assentimento: nesta categoria encontram-se todas as pendências relacionadas a estes documentos. Foi considerado necessário subdividir em subcategorias devido à ampla gama de itens que contemplam a avaliação da conformidade destes termos. Assim, há três subcategorias: descrição inadequada ou incompleta de riscos, benefícios e formas de minimização, ausência ou inconformidade nos demais itens obrigatórios - informações básicas do proponente, informações do CEP, informações detalhadas sobre o projeto e como se dará a participação, possibilidade de desistência, direitos a assistência, garantia de confidencialidade e sigilo das informações, gastos da pesquisa, indenização no caso de danos, elaboração em duas vias e a posse de uma para o participante - e redação incompreensível, demasiadamente técnica ou inadequada nos termos;

b) questões metodológicas: compreendem as pendências relativas à falta de alinhamento dos objetivos de pesquisa com a metodologia definida ou com os instrumentos de coleta de dados apresentados, classificações metodológicas incompletas ou incorretas como, por exemplo, justificativa para o número de participantes envolvidos, cálculo amostral incoerente e ausência do instrumento de coleta de dados;

c) ausência ou inconformidades em itens ou documentos obrigatórios do projeto: esta categoria divide-se nas seguintes subcategorias: folha de rosto, documento de registro do projeto no Gabinete de Projetos, termo de confidencialidade, autorização institucional, cronograma e orçamento;

d) inconsistência entre as informações fornecidas: quando no projeto, no cadastro da Plataforma Brasil e nos documentos anexados na Plataforma Brasil há informações diferentes para o mesmo assunto.

\section{O Comitê de Ética em Pesquisa com seres humanos da Universidade Federal de Santa Maria}

O CEP/UFSM foi escolhido como local de estudo devido a sua relevância social para a região na qual se insere. $O$ primeiro comitê da instituição foi em caráter provisório e estava vinculado ao Centro de Ciências da Saúde, contando com a participação de docentes do centro e mais um religioso representando a categoria de usuários. Além da demanda da própria universidade, o CEP/UFSM atendia outras instituições da região. Os trabalhos estavam direcionados a divulgar a recente normativa e oferecer suporte às submissões de projetos (Weis et al., 2011). Em 1999, devido ao aumento da demanda por avaliação de projetos provenientes de outras áreas do conhecimento, foi criado um CEP adicional para atendê-las, com vinculação na Pró-Reitoria de Pós-Graduação e Pesquisa. Durante um período os dois CEPs coexistiram na instituição, porém, em 2006, optou-se por extinguir o CEP/CCS e tornar o CEP/PRPGP único, com composição multidisciplinar (Weis et al., 2011).

Atualmente o CEP/UFSM tem 21 integrantes: sete representantes do Centro de Ciências da Saúde, um do Centro de Ciências Sociais e Humanas, um do Centro de Ciências Rurais, um do Centro de Educação, um do Centro de Artes e Letras, um do 
Hospital Universitário de Santa Maria, dois do campus de Palmeira das Missões, dois do campus de Frederico Westphalen, três representantes dos usuários e dois de instituições vinculada. Todos os projetos recebidos na secretaria, por meio da Plataforma Brasil, são avaliados por, pelo menos, um dos integrantes e, posteriormente, são relatados na reunião do colegiado que ocorre mensalmente. Das decisões da reunião é emitido um parecer consubstanciado, o qual é remetido ao pesquisador responsável pelo projeto proposto. Semestralmente encaminha-se à Conep o relatório de suas atividades e, a cada três anos, é necessário fazer um re-credenciamento, concedido caso o comitê se enquadre em todos os requisitos da Conep. Nas avaliações dos projetos, inicialmente, é realizada uma pré-análise pela secretaria, quando é feita a checagem da documentação anexada. Os seguintes documentos são requeridos na avaliação:

a) folha de rosto: documento gerado pela Plataforma Brasil em que consta o título do projeto, área de conhecimento CNPq, número de participantes envolvidos e dados pessoais do pesquisador proponente. $\mathrm{O}$ mesmo assina, declarando o conhecimento da legislação de ética em pesquisa aplicável, comprometendo-se a utilizar os dados coletados somente para os fins previstos e publicá-los, independentemente dos resultados obtidos. Após a assinatura do proponente há espaço para a assinatura da chefia imediata do mesmo, autorizando a execução do projeto, declarando obediência às Resoluções do CNS e às condições institucionais para a realização da pesquisa. Por fim, caso a pesquisa tenha um patrocinador, além do próprio pesquisador, há um terceiro espaço para a assinatura do financiador;

b) comprovante de registro no Gabinete de Projetos da UFSM: aplicável somente nos projetos da própria instituição. Compreende um registro institucional, avaliado por diversas instâncias, que possui informações relativas ao objetivo da pesquisa, justificativa, cronograma, participantes, resultados esperados e plano de trabalho detalhado;

c) termo de confidencialidade: documento assinado pelo proponente da pesquisa, comprometendo-se a preservar a confidencialidade dos dados dos participantes envolvidos e utilizá-los somente para os fins da pesquisa, de forma anônima. Também, informa o endereço onde os dados serão armazenados por um período de cinco anos, sob posse do proponente;

d) autorização institucional: documento assinado pelo responsável do setor, unidade ou instituição em que os dados serão coletados, demonstrando a ciência e autorização para execução do estudo;

e) termo de consentimento livre e esclarecido: documento em que o participante da pesquisa obtém todas as informações a respeito do protocolo no qual poderá fazer parte $\mathrm{e}$ assina caso concorde com a participação. Contém itens obrigatórios como: dados para contato com o responsável pela pesquisa, dados para contato com o comitê de ética que aprovou o protocolo, objetivos da pesquisa, justificativa, procedimentos, forma de participação, riscos e benefícios previstos, esclarecimento da possibilidade de não aceitar participar ou desistir a qualquer tempo sem prejuízos, garantia de assistência gratuita caso necessário, confidencialidade dos dados, isenção de gastos decorrentes da pesquisa, garantia de indenização em caso de danos comprovados decorrentes da participação e a posse de uma via do documento.

f) termo de assentimento: documento que precisa conter as mesmas informações do TCLE, porém com linguagem acessível aos participantes menores de idade;

\begin{tabular}{|l|l|l|l|l|l|}
\hline Regae: Rev. Gest. Aval. Educ. & Santa Maria & v. 10 & n. 19 & e67392, p. 1-14 & 2021 \\
\hline
\end{tabular}


g) projeto de pesquisa: contendo introdução, referencial teórico, metodologia, cronograma, orçamento, instrumento de coleta de dados, e os documentos supracitados acima;

Após a checagem da documentação, encaminha-se o processo a um dos integrantes avaliadores para leitura e análise dos aspectos éticos. Este emite um parecer que será lido e discutido em reunião mensal do colegiado. A partir da segunda avaliação não é necessário o relato do projeto em reunião, sendo verificado pelo relator o atendimento das pendências e emissão de novo parecer. Quanto ao número de pareceres avaliados, há dados que seguem.

Tabela 1 -

Números e situação dos pareceres emitidos no período de 2016 a 2019 pelo CEP/UFSM.

\begin{tabular}{l|c|c|c|c}
\hline \multicolumn{1}{c|}{ Situação } & 2016 & 2017 & 2018 & 2019 \\
\hline Aprovado & 414 & 477 & 424 & 417 \\
\hline Pendente & 280 & 330 & 210 & 209 \\
\hline Retirado & 14 & 40 & 9 & 15 \\
\hline Não-aprovado & 4 & 10 & 6 & 2 \\
\hline Emendas/notificações & 92 & 90 & 96 & 115 \\
\hline Total & 804 & 947 & 745 & 758 \\
\hline
\end{tabular}

Fonte: Plataforma Brasil (2020).

\section{Estratificação das pendências mais recorrentes}

Por meio da análise de conteúdo foram mapeadas e definidas as categorias e subcategorias. A seguir, apresentam-se os resultados obtidos.

Tabela 2 -

Categoria 'TCLE/Assentimento' de 2016 a 2019 no CEP/UFSM.

\begin{tabular}{c|c|c|c|c|c}
\hline Subcategorias & 2016 & 2017 & 2018 & 2019 & Total \\
\hline Riscos e Benefícios & 44 & 53 & 33 & 28 & 158 \\
\hline Itens obrigatórios & 34 & 36 & 17 & 31 & 118 \\
\hline Redação dos Termos & 22 & 38 & 19 & 24 & 103 \\
\hline Total de pendências & 100 & 127 & 69 & 83 & 379 \\
\hline
\end{tabular}

Fonte: autores (2020).

As pendências relativas a esta categoria representam $40,97 \%$ do total de pendências identificadas nos pareceres. O TCLE/assentimento é o documento que precisa conter todas as informações detalhadas para o participante decidir se irá aceitar ou não participar da pesquisa. Essa é a forma de assegurar todos os direitos dos participantes e os deveres do proponente. Por esse motivo, ao redigir esses termos, devese colocar no lugar da pessoa que irá ler, observando as características da população participante, como escolaridade, cultura e condição econômica (Brasil, 2020). O resultado vai ao encontro dos resultados de Massarollo, Kurcgant e Fernandes (2009), cujas 
pendências encontradas no TCLE corresponderam a $56,4 \%$ do total de pendências analisadas. Todavia, dentro do TCLE, a subcategoria com maiores índices diz respeito a redação dos termos, com $21,1 \%$ do total.

É importante a previsão de todos os riscos que envolvem a participação de forma que um participante não aceite participar de um protocolo sem estar ciente das possíveis adversidades que poderão ocorrer e quais os benefícios advindos. Isso é relevante até mesmo para a ponderação entre o risco que estaria disposto a correr em detrimento dos futuros benefícios. Em $17,08 \%$ das pendências encontradas, os riscos e suas formas de minimização e os benefícios não estavam adequadamente caracterizados. Em 12,75\% das pendências havia ausência de itens obrigatórios. Para $11,14 \%$ das avaliações realizadas pelo CEP a redação dos termos estava excessivamente técnica e poderia ser incompreensível para a população em estudo, ou com frases incoerentes e inadequadas.

A resolução n. 466/2012 é direta no que diz respeito a essa questão: "conter todas as informações necessárias, em linguagem clara e objetiva, de fácil entendimento, para o mais completo esclarecimento sobre a pesquisa a qual se propõe participar" (Brasil, 2012, p. 3). Dessa forma, destaca-se que, a fim de mitigar o significativo número de pendência relativas a esses termos, pode-se elaborar manuais específicos ou minicursos para elaboração de TCLEs e assentimentos, abrangendo formas de abordagens para diferentes públicos.

Outra categoria com quantidade considerável de pendências encontradas diz respeito a 'questões metodológicas', cujos dados estão estratificados na tabela 3.

Tabela 3 -

Questões metodológicas de 2016 a 2019 no CEP/UFSM.

\begin{tabular}{l|c|c|c|c|c}
\hline Subcategorias & 2016 & 2017 & 2018 & 2019 & Total \\
\hline Falta de alinhamento & 10 & 7 & 4 & 3 & 24 \\
\hline Classif. Metodológicas & 31 & 43 & 25 & 23 & 122 \\
\hline Ausência de instrumento & 8 & 12 & 8 & 8 & 36 \\
\hline Total de pendências & 49 & 62 & 37 & 34 & 182 \\
\hline
\end{tabular}

Fonte: autores (2020).

As pendências relativas às questões metodológicas representam $19,26 \%$ do total de pendências apuradas. Um estudo de Barbosa (2010) teve como um dos resultados o fato de que os pesquisadores apresentam dificuldades de compreensão da necessidade de avaliação dos aspectos metodológicos pelos CEPs. Entretanto, a resolução n. 466/2012 correlaciona a análise dos aspectos éticos com a análise do método empregado no protocolo (Brasil, 2012), e a resolução n. 510/2016 prevê que deve ser avaliado o método nos procedimentos que impliquem riscos aos participantes, mas não o delineamento, desenho do estudo (Brasil, 2016).

Considerando as resoluções supracitadas, as pendências relativas à ausência de instrumento, que correspondem a 3,89\% do total, são pertinentes devido à possibilidade de riscos na aplicação do mesmo. As demais subcategorias podem ser questionadas quanto à sua validade. Acerca disso Spiandorello (2014) explica que a avaliação metodológica é importante de ser realizada pelos CEPs, pois confere confiabilidade às pesquisas, não aprovando projetos cujo método não é capaz de responder ao problema

\begin{tabular}{|l|l|l|l|l|l|}
\hline Regae: Rev. Gest. Aval. Educ. & Santa Maria & v. 10 & n. 19 & e67392, p. 1-14 & 2021 \\
\hline
\end{tabular}


de pesquisa proposto. Dessa maneira, evita-se expor participantes a riscos e danos desnecessários e à consecução de projetos sem validade científica. Sugere-se que sejam abordados aspectos éticos associados à questão metodológica nas disciplinas de metodologia da pesquisa, de forma que o tema passe a ser cada vez mais familiar para a comunidade acadêmica.

Quanto às pendências relacionadas aos itens e demais documentos obrigatórios, na tabela 4 se demonstram os resultados.

Tabela 4 -

Categoria 'itens e demais documentos obrigatórios' de 2016 a 2019 no CEP/UFSM.

\begin{tabular}{l|c|c|c|c|c}
\hline \multicolumn{1}{c|}{ Subcategorias } & 2016 & 2017 & 2018 & 2019 & Total \\
\hline Folha de rosto & 2 & 4 & 1 & 1 & 8 \\
\hline Registro no GAP & 1 & 2 & 2 & 2 & 7 \\
\hline T. de confidencialidade & 17 & 13 & 9 & 6 & 45 \\
\hline Aut. Institucional & 18 & 29 & 15 & 19 & 81 \\
\hline Cronograma & 30 & 36 & 8 & 8 & 82 \\
\hline Orçamento & 7 & 6 & 0 & 2 & 15 \\
\hline Total de pendências & 75 & 90 & 35 & 38 & 238 \\
\hline
\end{tabular}

Fonte: autores (2020).

Essa categoria corresponde a $25,73 \%$ do total de pendências encontradas, porém considera-se que, comparativamente às categorias anteriores, o número é moderado, uma vez que envolve um número significativamente maior de subcategorias. Destacamse, entre elas, as pendências relativas ao termo de confidencialidade (4,86\%), autorização institucional $(8,76 \%)$ e cronograma $(8,86 \%)$. Em relação ao primeiro as principais inconformidades se referem à responsabilidade pela guarda dos dados coletados, que deve ser do professor orientador do projeto e não do aluno orientado. Já em relação à autorização institucional, o principal motivo encontrado de inconformidade é a ausência do documento ou o documento assinado por uma autoridade que não é aquela competente para autorizar a pesquisa. No cronograma o principal motivo de pendência se refere ao início da coleta de dados que só pode ocorrer após a aprovação do CEP. De modo geral, essa categoria refere-se mais às questões formais dos documentos, situação que pode ser contornada com a criação de manuais específicos.

Por fim, a última categoria refere-se às diferenças de informações fornecidas no projeto, no cadastro da Plataforma Brasil e nos documentos anexados na Plataforma Brasil.

Tabela 5 -

Categoria 'informações discordantes fornecidas no projeto, PB e documentos anexados' de 2016 a 2019 no CEP/UFSM.

\begin{tabular}{l|c|c|c|c|c}
\hline \multicolumn{1}{c|}{ Categoria } & 2016 & 2017 & 2018 & 2019 & Total \\
\hline Inconsistências & 40 & 43 & 20 & 23 & 126 \\
\hline Total de pendências & 40 & 43 & 20 & 23 & 126 \\
\hline
\end{tabular}

Fonte: autores (2020). 
Essa categoria, que corresponde a $13,33 \%$ do total de pendências, refere-se a informações conflitantes para o mesmo assunto, identificadas nos diversos locais onde precisam estar inseridas. Isso ocorre, porque, por exemplo, a informação relativa a riscos e benefícios e número de participantes da pesquisa precisam estar em três locais distintos: no projeto, no TCLE e nas informações preenchidas na Plataforma Brasil. Isso acontece com vários itens, visto que a Plataforma pede o preenchimento de uma série de informações que também podem ser encontradas no projeto ou nos documentos anexados separadamente.

É reconhecido que tal pendência pode ser considerada um lapso por parte do pesquisador no momento da submissão, porém, é importante que seja ressaltado um dos possíveis motivos para a sua ocorrência. Muitas vezes, pesquisadores lidam com prazos curtos, elevada demanda de trabalho e se deparam com quantidades consideráveis de informações e documentos necessários para a avaliação do CEP. Para contornar essas dificuldades poderia haver fusão entre os documentos e redução desse formalismo. Tal constatação vai ao encontro do que afirma Tomanik (2008), que muitas vezes os CEPs acabam tornando-se muito técnicos e voltados para formalidades burocráticas, em vez de se pautarem em debates a respeito dos protocolos apresentados pelos pesquisadores a partir do viés ético. Tal fato acaba por distanciar ainda mais o comitê dos pesquisadores que, ao contrário, devem aproximar-se do seu público, assumindo uma conduta educativa, complacente e ágil na avaliação de projetos (Barbosa; Corrales; Silbermann, 2014).

\section{Considerações finais}

A preocupação com as questões éticas nas pesquisas tem se intensificado no Brasil, onde a primeira regulamentação surgiu em 1988 e pode ser considerada jovem, levandose em conta que o primeiro documento internacional a respeito do tema, o Código de Nuremberg, lançado 41 anos antes. O fato é que com a existência de resoluções norteadoras e a iminência do surgimento de legislação federal que obrigue a avaliação ética de projetos, as instituições devem buscar o aprimoramento de seus comitês de ética em pesquisa. Baseado nisso, este trabalho objetivou identificar as pendências mais recorrentes nos pareceres emitidos pelo Comitê de Ética em Pesquisa com Seres Humanos da Universidade Federal de Santa Maria, a fim de se buscar melhorias para aperfeiçoar o processo dentro da Instituição

Inicialmente foi realizada a caracterização do funcionamento do CEP/UFSM com vistas a conhecer como o mesmo se organiza estruturalmente e conduz as atividades de recebimento e avaliação de projetos de pesquisa. Após isso foram verificadas as principais pendências nos pareceres emitidos pelos avaliadores de projetos na Plataforma Brasil entre os anos de 2016 a 2019. Observou-se que 40,97\% das pendências são relativas à descrição de riscos e benefícios, redação e inclusão de itens obrigatórios no termo de consentimento livre e esclarecido e no termo de assentimento. Na sequência, com $25,73 \%$ do total, estão as pendências relacionadas aos demais documentos obrigatórios, como o termo de confidencialidade, por exemplo, com ausência de informações ou informações discordantes, bem como aspectos formais como assinatura. Em terceiro lugar, com 19,26\%, ficaram as pendências relacionadas à metodologia dos projetos, que muitas vezes apresentaram falta de alinhamento com os objetivos traçados,

\begin{tabular}{|l|l|l|l|l|l|}
\hline Regae: Rev. Gest. Aval. Educ. & Santa Maria & v. 10 & n. 19 & e67392, p. 1-14 & 2021 \\
\hline
\end{tabular}


classificação incorreta ou ausência de informações relevantes para a avaliação. Por fim, com $13,33 \%$, ficaram as pendências relativas a uma mesma informação que foi apresentada de forma distinta em locais diferentes, como, por exemplo, o número da amostra ser diferente na Plataforma Brasil e no projeto.

Concluiu-se que os usuários concentram suas principais dificuldades em elaborar o TCLE de acordo com o tipo de pesquisa que realizam e com a legislação aplicável, bem como elaborar os demais documentos necessários de forma que atenda os requisitos do CEP/UFSM. Para estes casos é importante que o CEP promova capacitações e treinamentos, bem como cartilhas ou manuais específicos para áreas de conhecimento e suas especificidades. Também convém explicitar quais os aspectos metodológicos passam pelo escopo de sua avaliação, fator este responsável pelo terceiro maior número de pendências.

Como limitação metodológica deste estudo entende-se que a identificação de pendências a partir das evidências coletadas na Plataforma Brasil possa limitar a análise, sem a possibilidade de identificar se os pesquisadores que submeteram projetos têm conhecimento acerca da normatização sobre ética em pesquisa com seres humanos e outros aspectos relacionados.

\section{Referências}

ARAÚJO, Nelma Camelo; FRANCISCO, Deise Juliana. Ética em pesquisa com seres humanos na web: o caso da Plataforma Brasil. Informação \& Informação, Londrina, v. 21, n. 3, 2016, p. 361-375

BARBOSA, Adriana Silva. Entraves e potencialidades dos comitês de ética em pesquisa (CEPS) das universidades estaduais da Bahia. Jequié: Uesb, 2010. 185f. Dissertação (Mestrado em Enfermagem e Saúde). Universidade Estadual do Sudoeste da Bahia.

BARBOSA, Adriana Silva; CORRALES, Carlos Monteiro; SILBERMANN, Marcos. Controvérsias sobre a revisão ética de pesquisas em ciências humanas e sociais pelo Sistema CEP/Conep. Revista Bioética, Brasília, v. 22, n. 3, 2014, p. 482-492.

BARDIN, Laurence. Análise de conteúdo. São Paulo: Edições 70, 2011.

BRASIL. Ministério da Saúde. Conselho Nacional de Saúde. Comissão Nacional de Ética em Pesquisa. Manual operacional para comitês de ética em pesquisa. 4. ed. rev. atual. Brasília: Ministério da Saúde, 2008.

BRASIL. Resolução normativa n. 466, de 12 de dezembro de 2012: aprova diretrizes e normas regulamentadoras de pesquisas envolvendo seres humanos. Diário Oficial da União: seção 1, Brasília, DF, n. 12, p. 59, 13 dez. 2012. Disponível em: http://bvsms.saude.gov.br/bvs/saudelegis/cns/2013/res0466_12_12_2012.html. Acesso em: 25 jul. 2019.

BRASIL. Ministério da Saúde. Conselho Nacional de Saúde. Resoluções. Brasília: Ministério da Saúde, 2020. Disponível em: http://conselho.saude.gov.br/resolucoes-cns. Acesso em: 02 jul. 2020.

CERVO, Amado Luiz; BERVIAN, Pedro Alcino; DA SILVA, Roberto. Metodologia científica. São Paulo: Pearson Prentice Hall, 2007.

CONSELHO NACIONAL DE SAÚDE. Comitês de ética em pesquisa. Brasília: CNS, 2021. Disponível em: http://conselho.saude.gov.br/comites-de-etica-em-pesquisaconep?view=default. Acesso em: 01 abr. 2021. 
FREITAS, Corina Bomtempo Duca Freitas; HOSSNE, William Saad. O papel dos comitês de ética em pesquisa na proteção do ser humano. Revista Bioética, Brasília, v. 10, n. 2, 2002, p. 129-146.

GRISOTTI, Márcia. A ética em pesquisa com seres humanos: desafios e novas questões. Revista Brasileira de Sociologia, Porto Alegre, v. 3, n. 5, 2015, p. 159-176.

GUERRIERO, lara Coelho Zito. Resolução n. 510 de 7 de abril de 2016 que trata das especificidades éticas das pesquisas nas ciências humanas e sociais e de outras que utilizam metodologias próprias dessas áreas. Ciência \& Saúde Coletiva, Rio de Janeiro, v. 21, n. 8, 2016, p. 2619-2629.

GUILHEM, Dirce; DINIZ, Débora. O que é ética em pesquisa. São Paulo: Brasiliense, 2014.

LOPES-JÚNIOR, Luís Carlos et al. Dificuldades e desafios em revisar aspectos éticos das pesquisas no Brasil. Revista Gaúcha de Enfermagem, Porto Alegre, v. 37, n. 2, 2016, p. 1 5.

LOPES, Luis Felipe Dias. Calcule o tamanho da amostra para sua pesquisa. 2020. Disponível em: http://felipelopes.com/CalculoAmostra.php. Acesso em: 12 mar. 2020.

MASSAROLLO, Maria Cristina Komatsu Braga; KURCGANT, Paulina; FERNANDES, Maria de Fátima Prado. Comitê de Ética em Pesquisa da Escola de Enfermagem da Universidade de São Paulo: experiência dos primeiros seis anos. Revista da Escola de Enfermagem da USP, São Paulo, v. 43, n. esp., 2009, p. 1303-1307.

MELLO, Anahi Guedes. Deficiência, incapacidade e vulnerabilidade: do capacitismo ou a preeminência capacitista e biomédica do Comitê de Ética em Pesquisa da UFSC. Ciência \& Saúde Coletiva, Rio de Janeiro, v. 21, n. 10, 2016, p. 3265-3276.

NETO, João Beccon de Almeida; FRANCO, Túlio Batista. Análise das publicações sobre os comitês de ética em pesquisa em Scientific Eletronic Library Online (Scielo). Revista Latinoamericana de Bioética, Colômbia, v. 36, 2019, p. 27-50.

NOVOA, Patrícia Correia Rodrigues. O que muda na ética em pesquisa no Brasil: resolução 466/12 do Conselho Nacional de Saúde. Einstein, São Paulo, v. 12, n. 1, 2014, p. 7-10.

PLATAFORMA BRASIL. 2019. Disponível em: http://plataformabrasil.saude.gov.br/login.jsf. Acesso em: 10 ago. 2019.

REGO, Sérgio; PALÁCIOS, Marisa. Comitês de ética em pesquisa: teoria e prática. Rio de Janeiro: Fiocruz, 2012.

ROSSI, George Bedinelli; SERRALVO, Francisco Antonio; JOÃO, Belmiro Nascimento. Análise de conteúdo. Revista Brasileira de Marketing, São Paulo, v. 13, n. 4, 2014, p. 3948.

SPIANDORELLO, Wilson Paloschi. O papel do comitê de ética em pesquisa na avaliação de testes estatísticos. Revista Bioética, Brasília, v. 22, n. 3, 2014, p. 471-481.

SWAIN, Frank É certo usar a ciência nazista para salvar vidas? BBC, [S. I.], 28 jul. 2019. Disponível em: https://www.bbc.com/portuguese/geral-49122992. Acesso em: 8 set. 2019.

TRIBUNAL INTERNACIONAL DE NUREMBERG. Código de Nuremberg 1947. Disponível em: https://www.ufrgs.br/bioetica/nuremcod.htm. Acesso em: 25 jul. 2019.

UFSM. Núcleo de comitês. Santa Maria, 2019. Disponível em: http://nucleodecomites.ufsm.br/. Acesso em: 1ํ dez. 2019. 
WEIS, Luiza Nardin et al. O comitê de ética em pesquisa na Universidade Federal de Santa Maria: um breve histórico. Revista HCPA, Porto Alegre, v. 31, n. 3, 2011, p. 372376.

Gabriela Heinz é contadora na Universidade Federal de Santa Maria.

Orcid: https://orcid.org/0000-0003-2536-7573.

Endereço: Av. Roraima, 1000, prédio 64A - 97105-900 - Santa Maria - RS- Brasil.

E-mail:gabheinzz@gmail.com.

Luis Carlos Zucatto é professor na Universidade Federal de Santa Maria.

Orcid: https://orcid.org/0000-0003-0731-9180.

Endereço: Avenida Independência, 3751 - 98300-000 - Palmeira das Missões - RS Brasil.

E-mail: luiszucatto@gmail.com.

Critério de autoria: os dois autores conceberam a ideia. Gabriela coletou, analisou os dados e preparou a primeira versão. Os dois autores discutiram os resultados e contribuíram para a versão final do manuscrito.

Recebido em 26 de agosto de 2021.

Aceito em 29 de outubro de 2021

(c) (1) (\$) $\odot$ 